\title{
Efficacy of High Dose Tranexamic Acid in Decreasing Bleeding after Cardiac Surgery for Cyanotic Congenital Heart Disease in Children Less than Ten Kilo Body Weight
}

\author{
Saranya Vishnumathy Sampathkumar1, Vijayakumar Raju², Soundaravalli Balakrishnan1, \\ Saigopalakrishnan Mandhira Moorthy', Anandhi Arul'1, Kalyana Sundaram Muthuswamy33, \\ Muralidharan Srinivasan²
}

\author{
${ }^{1}$ Division of Cardiac Anesthesia, G. Kuppusamy Naidu Memorial Hospital, Coimbatore, India \\ ${ }^{2}$ Pediatric Cardiac Surgery, G. Kuppusamy Naidu Memorial Hospital, Coimbatore, India \\ ${ }^{3}$ Pediatric Cardiology, G. Kuppusamy Naidu Memorial Hospital, Coimbatore, India \\ Email: *vijraju@hotmail.com
}

How to cite this paper: Sampathkumar, S.V., Raju, V., Balakrishnan, S., Moorthy, S.M., Arul, A., Muthuswamy, K.S. and Srinivasan, M. (2018) Efficacy of High Dose Tranexamic Acid in Decreasing Bleeding after Cardiac Surgery for Cyanotic Congenital Heart Disease in Children Less than Ten Kilo Body Weight. World Journal of Cardiovascular Surgery, 8, 93-102. https://doi.org/10.4236/wjcs.2018.85008

Received: March 4, 2018

Accepted: May 7, 2018

Published: May 10, 2018

Copyright $(9) 2018$ by authors and Scientific Research Publishing Inc. This work is licensed under the Creative Commons Attribution International License (CC BY 4.0).

http://creativecommons.org/licenses/by/4.0/

\begin{abstract}
Background: To determine the effect of high dose tranexamic acid in decreasing immediate postoperative bleeding in children less than ten kilo body weight after complex cardiac surgery and also to evaluate the safety of high dose in small children. Methods: Between January-December 2015, 25 children weighing less than ten kilogram body weight underwent complex cardiac surgery for cyanotic congenital heart disease. All children were given dose of $100 \mathrm{mg} / \mathrm{kg}$ tranexamic acid at the time of anaesthetic induction and also 100 $\mathrm{mg} / \mathrm{kg}$ into the CPB prime. The Median age and weight was 80 days (3 - 365) and $4.69 \mathrm{~kg}(2.4-7.8)$ respectively. The Median preoperative $\mathrm{Hb}$ was $10 \mathrm{~g} / \mathrm{dl}$ (9.6 - $19.5 \mathrm{~g} / \mathrm{dl})$. Cardiac surgery included total intracardiac repair for TOF in 10 pts $(40 \%)$, TAPVC repair in $6(24 \%)$, arterial switch operation in 6 pts (24\%), BD glenn in 1, repair of DORV with VSD in 1 and VSD closure with scimitar vein reimplantation in $1 \mathrm{pt}$. Median CPB time was 127 minutes (97$343)$ and cross clamp time was $99(67$ - 200) minutes. Moderate to deep hypothermia was maintained in all with median temperature of $24^{\circ} \mathrm{C}(18-32)$. Three children (12\%) had elective open chest in view of anticipated bleeding. Results: The Median postoperative drainage was $127 \mathrm{ml}$, (range $10-1250 \mathrm{ml}$ ). The median postoperative use of whole blood was $95 \mathrm{ml}$ (range $10-275$ ), packed cell was $187 \mathrm{ml}$ (range $50-400 \mathrm{ml}$ ), frozen plasma was $88 \mathrm{ml}$ (range 30 - 170), platelet concentrate was $57 \mathrm{ml}$, (range 10 - $100 \mathrm{ml}$ ) and cryoprecipitate was median $47.5 \mathrm{ml}$, (range $30-80 \mathrm{ml}$ ). No neurological dysfunction and renal dysfunction has been observed in any of the pts. Out of 4 mortalities (16\%),
\end{abstract}


only one was attributed to bleeding (4\%) due to usage of ECMO. No late neurological or renal dysfunction has been observed in remaining 21 pts on follow up. Conclusion: High dose Tranexamic acid can be safely used in small children during complex cardiac surgery with significant reduction in postoperative bleeding and blood product usage without any higher incidence of neurological, renal dysfunction or myocardial infarction.

\section{Keywords}

Pediatric Cardiac Surgery, Bleeding, Antifibrinolytics, Tranexamic Acid, Renal Dysfunction, Neurological Dysfunction

\section{Introduction}

Cardiovascular surgery is always accompanied by perioperative bleeding as a result of cardiopulmonary bypass $(\mathrm{CPB})$ leading to alteration of coagulation cascade [1]. The most common causes of excessive bleeding in cardiac surgical patients have been related to the interaction of blood components with the artificial surfaces of the $\mathrm{CPB}$ pump circuit resulting in derangements in platelet function, impairment of coagulation system and excessive fibrinolysis. Neonates, smaller children (less than ten kilo) and children with cyanotic congenital heart disease are at increased risk of bleeding after cardiac surgery. It is due to immature clotting system and more complex procedure needing longer CPB timing. The application of hypothermia in children during cardiac surgery will also result in a general slowing of proteolytic enzyme activity, reduced fibrin synthesis and reduced platelet function and thereby increases the perioperative bleeding [2] [3].

Antifibrinolytics (Aprotinin and Tranexamic acid) are routinely used during cardiac surgery in children with complex cyanotic congenital heart disease and their benefits are very well established [4] [5]. Recently Aprotinin has been withdrawn from the market in view of its multiple side effects and hence no longer available in the market. Tranexamic acid is a synthetic lysine analogue which acts by reversibly blocking the lysine binding sites of plasminogen, thus preventing its activation to plasmin [1]-[6]. The usage of Tranexamic acid has increased dramatically after withdrawal of Aprotinin since 2007. But very few randomized studies and meta analysis are available in the literature about the safety of Tranexamic acid and its effect on bleeding and reduction in blood transfusion and related complications [6]. Even very few studies are available about the safety of Tranexamic acid in neonates and smaller children [6] [7] [8]. The dose at which tranexamic acid is effective is controversial. There is a large variation in the literature regarding dosage of Tranexamic acid starting from 1 $\mathrm{mg}$ to $100 \mathrm{mg} / \mathrm{kg}$ in children undergoing pediatric cardiac surgery. A land mark paper from Boston Children Hospital, USA by Lin C.-Y. et al. [9] have recommended use of high dose Tranexamic acid. The protocol proposed by Lin C.-Y. 
et al. consist of administering a bolus of $100 \mathrm{mg} / \mathrm{kg}$ of tranexamic acid to the patient after induction of anaesthesia, followed by an infusion of $10 \mathrm{mg} / \mathrm{kg} / \mathrm{h}$ until the end of the operation and $100 \mathrm{mg} / \mathrm{kg}$ was added to the CPB priming fluid. This protocol showed greater reduction in perioperative blood loss without any increase in the side effects [9].

\section{Objective of the Study}

1) To determine the effect of high dose TA on blood loss and postoperative drainage during paediatric cardiac surgery.

2) To determine the blood product usage in the postoperative period.

3) To report any incidence of neurologic, renal or any other side effect of high dose TA in neonate and smaller children

\section{Materials and Methods}

The Institutional Ethical committee has approved this retrospective, nonrandomized study, and the approval included a waiver of informed consent. Data were collected from a retrospective review of prospectively collected data. The study period was from January 2015 to December 2015. A total of 25 patients were included in this study. Peri operative data including postoperative bleeding and total replacement of blood and blood products were obtained from anesthesia records, perfusion data base, operative notes, ICU progress notes and nurses records. The anticipated side effects of TA included neurological events, renal or myocardial infarction. The neurological events in the form of new onset of seizure either focal or generalized, Transient ischemic attacks, abnormal movements, extrapyramidal signs and symptoms, altered speech and hemiparesis were included. EEG is available in our hospital in case of any seizure activity. Renal impairment was defined as rise of creatinine more than twice the preoperative value or rise of creatinine more than $1.2 \mathrm{mg} / \mathrm{dl}$ or the need for new onset peritoneal dialysis. Myocardial infarction was defined by new ECG changes along with new onset regional wall motion abnormalities in the Echocardiogram. All data were entered into the Microsoft excel sheet for further analysis. Data are expressed as median with range and qualitative variables were expressed as a percentage. There were no control group since it was retrospective study.

\subsection{Dose of Tranexamic Acid (TA)}

All these infants received TA at a dosage of $100 \mathrm{mg} / \mathrm{kg}$ at the time of induction of anesthesia as a bolus and $100 \mathrm{mg} / \mathrm{kg}$ of TA was added in to the CPB pump prime. The maximum dose limit of TA was $2 \mathrm{~g}$. The infusion of $10 \mathrm{mg} / \mathrm{kg} / \mathrm{hour}$ was only used if there is ongoing blood loss with persistent coagulopathy.

\subsection{Anasthesia and CPB Management}

All our children received sevofluorane inhaled anesthesia along with opioids and 
short acting muscle relaxants. Methylprednisolone was given at $30 \mathrm{mg} / \mathrm{kg}$ for all neonate and children needing deep hypothermic circulatory arrest. Blood prime along with Fresh Frozen Plasma (FFP) was used for all these patients and moderate to deep hypothermia was used in CPB. As a policy, our unit uses 3/16 inch tubing for arterial line in the $\mathrm{CPB}$ circuit in kids less than 3 kilo and 1/4 inch tubing was used for children more than 3 kilo to reduce priming volume. Ultrafiltration was used in all. Conventional ultrafiltration (CUF) was used in all and aiming for Zero balance at the end of the procedure. Cell saver was not available in our unit, hence we did not use in any of our children. Alpha stat PH management and ice around the head was used for children needing deep hypothermic circulatory arrest. Chest was left open in all neonates and children with unsatisfactory hemostasis and delayed chest closure was preferred.

\subsection{Target Haemoglobin}

Intraoperative haemoglobin $(\mathrm{Hb})$ was maintained around $10 \mathrm{~g} / \mathrm{dl}$ in all these children. Our transfusion strategy in the post operative period involves aiming for Haemoglobin of $12 \mathrm{~g} / \mathrm{dl}$ in neonates and children with cyanotic congenital heart disease and $10 \mathrm{~g} / \mathrm{dl}$ in children with acyanotic congenital heart disease.

\section{Results}

The demographic data of the population included in the study is depicted in Figure 1 and Figure 2. The cardiac surgical procedure involves complete repair of Tetralogy of Fallot in 10 children, Arterial Switch Operation in 6 children, obstructed supracardiac TAPVC repair in 4, intracardiac TAPVC repair in 2, B/L BD glenn, atrial septectomy and divison of MPA for tricuspid atresia in 1, correction of DORV with VSD in 1 and repair of SCIMITAR syndrome along with closure of large malaligned VSD in 1 . The median CPB time was 127 minutes (range 97 - $343 \mathrm{~min}$ ) and median cross clamp time 99 minutes (range 67 - 200 $\mathrm{min})$. The median temperature of all our children in the $\mathrm{CPB}$ was 24 degree Celsius (18 - 32) and median $\mathrm{Hb}$ in the CPB was $10 \mathrm{~g} / \mathrm{dl}$ (8.4 - 12).

The Median blood loss was about $127 \mathrm{ml}$ (range from $10-1250 \mathrm{ml}$ ). Only one baby who underwent delayed ASO for TGA with intact ventricular septum at 35 days of life, needed ECMO after ASO in order to support untrained left ventricle had excessive bleeding. The Median postoperative blood replacement was about $193 \mathrm{ml}$ (range from $10-1015 \mathrm{ml}$ ). Blood and product transfusion requirements are illustrated in Table 1 . Whole blood transfusion was given in 22 patients $(88 \%)$ at about $20 \mathrm{ml} / \mathrm{kg}$, FFP was given in 14 children (56\%) at about $18 \mathrm{ml} / \mathrm{kg}$. Cryoprecipitate was given in $4(16 \%)$ children at about $13 \mathrm{ml} / \mathrm{kg}$ and 10 children (40\%) required platelet concentrates (PC) at about $14 \mathrm{ml} / \mathrm{kg}$. There were four mortalities (16\%) observed in this group within 30 days after surgery and only one mortality (4\%) was due to excessive bleeding and drainage. The excessive bleeding was due to need of ECMO in a child after delayed ASO. The remaining three mortalities were due to pulmonary artery hypertensive crisis in 1 and low 


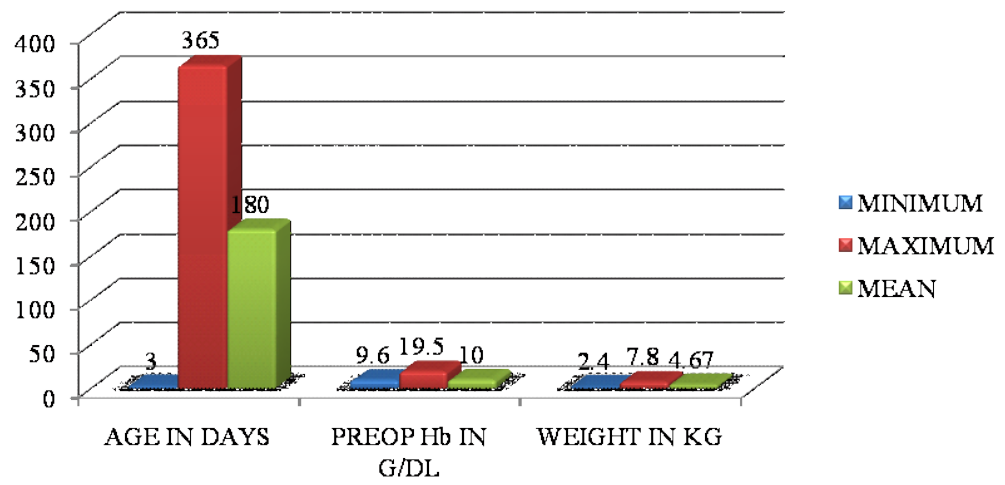

Figure 1. The Median age of the patient was 80 days (range 3 - 365 days). The median $\mathrm{Hb}$ level was $10 \mathrm{~g} / \mathrm{dl}(9.6-19.5 \mathrm{~g} / \mathrm{dl})$. The median weight recorded was $4.67 \mathrm{~kg}(2.4-7.8 \mathrm{~kg})$.

\section{CASE DISTRIBUTION - DIAGNOSIS}

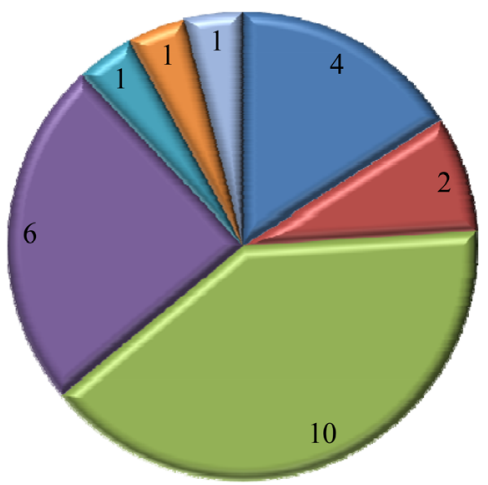

a SUPRACARDIAC TAPVC (4)

INTRACARDIAC TAPVC (2)

回OF (10)

田 TGA (6)

$\operatorname{aDORV}(1)$

口SCIMITAR SYNDROME(1)

田RICUSPID ATRESIA(1)

Figure 2. Preoperative cardiac diagnosis among children who underwent surgery.

cardiac output in 2 children due to ventricular failure (Figure 3 ). None of children in this study group any neurological, renal dysfunction or myocardial infarction in the postoperative period.

The median follow up was 22 months (12 months to 36 months). The complete follow up is available in $100 \%$ of alive patients. All the kids are doing well on the follow up with no onset of any new neurological or renal side effects. There are no long term mortality observed during follow up.

\section{Discussion}

Congenital heart defects are inherently associated with a deranged coagulation system with a pre-existing altered platelet function and altered fibrinolysis [10] [11] [12]. They are more prone for bleeding as these effects are worsened by CPB [6]. Antifibrinolytic agents are used routinely to complement the haemostasis in patients undergoing cardiac surgery.

Aprotinin was withdrawn from the market in 2007 due to high incidence of side effects and increased perioperative mortality. Some publications suggested 
Table 1. Blood and product transfusion requirements in the postoperative period.

\begin{tabular}{cccc}
\hline Products used & No of patients & $\begin{array}{c}\text { Percentage of patients } \\
\text { requiring product } \\
\text { transfusion }\end{array}$ & Requirement in ml/kg \\
\cline { 4 - 4 } & 22 & $88 \%$ & Mean value \\
\hline Whole blood & 14 & $56 \%$ & $20 \mathrm{ml} / \mathrm{kg}$ \\
FFP & 4 & $16 \%$ & $18 \mathrm{ml} / \mathrm{kg}$ \\
Cryoprecipitate & 10 & $40 \%$ & $13 \mathrm{ml} / \mathrm{kg}$ \\
Platelet concentrate & 4 & $16 \%$ & $14 \mathrm{ml} / \mathrm{kg}$ \\
PRBC & & & $25 \mathrm{ml} / \mathrm{kg}$ \\
\hline
\end{tabular}

FFP: Fresh Frozen Plasma, PRBC: Packed red blood cell.

\section{RESULTS}

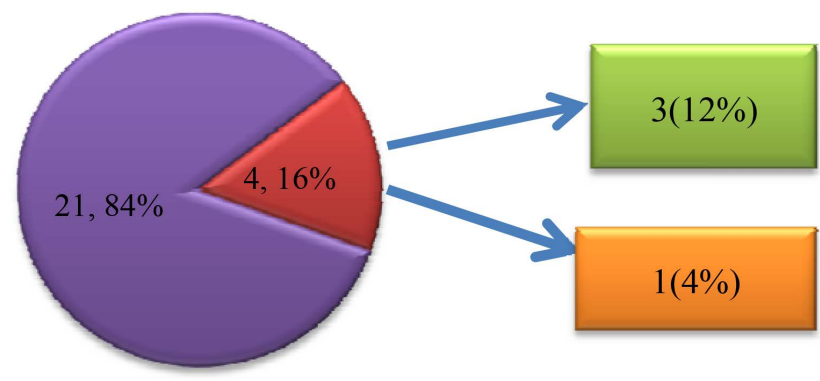

ॠO MORTALITY $\square$ MORTALITY

Figure 3. The Surgical outcome including 30 day mortality. NO MORTALITY: 21 (84\%); MORTALITY: 4 (16\%); MORTALITY DUE TO BLEEDING: 1 (4\%); MORTALITY DUE TO OTHER REASONS: 3 (12\%).

that the withdrawal of aprotinin has been detrimental to patients undergoing cardiac surgery due to increased adverse outcomes and use of blood products [13] [14] [15]. Since Aprotinin is no longer available, TA is now considered as the first line antifibrinolytics. TA, a synthetic analogue of the amino acid lysine, exerts its antifibrinolytic activity by competitive blockade of lysine binding sites on plasminogen to prevent its activation, and at higher concentrations, causes non-competitive inhibition of plasmin. Schindler et al.reported that aprotinin can be replaced with tranexamic acid because of the equal blood sparing effects, but they also indicated that the evidence accumulated at present remains insufficient to clearly estimate the benefits and risks associated with the use of tranexamic acid in congenital heart surgery [8].

There are few studies demonstrated neuorological side effects with use of TA [16] [17] [18] [19]. Hence indiscriminate use of TA and especially high dose TA is a matter of concern for majority. There is major variability in dosing of TA in the currently available literature including routes of administration, amount of drug given as loading dose, pump prime, infusion and duration of infusion. The dosing of TA is important because its side effects are dose related. Few studies demonstrated increased neurological side effect if the dose of TA exceed more than 10 gram [20] [21] [22]. We have used $100 \mathrm{mg} / \mathrm{kg}$ as a bolus and $100 \mathrm{mg} / \mathrm{kg}$ 
in the $\mathrm{CPB}$ prime with maximum dose not exceeding more than $2 \mathrm{~g}$. Continuous infusion of TA at $10 \mathrm{mg} / \mathrm{kg}$ was rarely used unless there is ongoing persistent coagulopathy. We did not observe any neurological, renal or cardiac dysfunction in our 25 patients in spite using high dose of TA (maximum dose of $2 \mathrm{~g}$ ).

The blood-conserving property of TA is uniformly reported by randomised and observational studies and in meta analyses without any increase in side effects or mortality [23] [24]. A meta analysis by Ngaage DL et al. [25] showed the mean chest tube drainage after cardiac surgery is less by about $283 \mathrm{ml}$ (95\% CI: $220-346, \mathrm{p}<0.001)$ with use of TA compared to placebo. Meta analysis also showed decrease in the risk of re-operation for bleeding by $48 \%$, transfusion of packed red cell by $47 \%$ and use of haemostatic blood products by $67 \%$ [25].

Bleeding in neonates and infants after cardiac surgery is a nightmare for any pediatric cardiothoracic surgeon. Multiple Transfusion of blood and blood products has shown to be independent risk factor for operative mortality in multiple studies. Currently available topical hemosealants are effective but they are very expensive. Recombinant Factor VII was used in very limited centers after pediatric cardiac surgery across the world and it is not a viable option in developing nations. TA is least expensive and remains a good choice of antifibrinolytic in developing nations.

\section{Conclusion}

TA may be used in pediatric congenital cardiac surgery effectively at this high dose as it was found to be effective in reducing postoperative blood loss and blood product usage. Carefully designed, randomised, controlled trials are needed to explore the real efficacy and the possible side effects of TA in pediatric cardiac surgery

\section{Limitations of the Study}

1) Retrospective study

2) Samller number of children

3) No control group to compare the real efficacy of high dose TA

4) Liberal use of blood and product transfusion to maintain $\mathrm{Hb}$ value of 12 $\mathrm{g} / \mathrm{dl}$ in the postoperative period despite usage of TA, so the genuine need for postoperative blood product usage after TA was masked.

\section{Funding}

This study was not funded any one.

\section{Conflict of Interest}

No.

\section{Ethical Approval}

All procedures performed in studies involving human participants were in ac- 
cordance with the ethical standards of the institutional and/or national research committee and with the 1964 Helsinki declaration and its later amendments or comparable ethical standards.

\section{Informed Consent}

This was a retrospective observational studies, hence Informed consent was waived off by our ethical Committee.

\section{References}

[1] Dunn, C.J. and Goa, K.L. (1999) Tranexamic Acid: A Review of Its Use in Surgery and Other Indications. Drugs, 57, 1005-1032. https://doi.org/10.2165/00003495-199957060-00017

[2] Faraoni, D., Willems, A., Melot, C., De Hert, S. and Van der Linden, P. (2012) Efficacy of Tranexamic Acid in Paediatric Cardiac Surgery: A Systematic Review and Meta-Analysis. European Journal of Cardio-Thoracic Surgery, 42, 781-786. https://doi.org/10.1093/ejcts/ezs127

[3] Zonis, Z., Seear, M., Reichert, C., Sett, S. and Allen, C. (1996) The Effect of Preoperative Tranexamic Acid on Blood Loss after Cardiac Operations in Children. The Journal of Thoracic and Cardiovascular Surgery, 111, 982-987. https://doi.org/10.1016/S0022-5223(96)70374-4

[4] Reid, R.W., Zimmerman, A.A., Laussen, P.C., Mayer, J.E., Gorlin, J.B. and Burrows, F.A. (1997) The Efficacy of Tranexamic Acid versus Placebo in Decreasing Blood Loss in Pediatric Patients Undergoing Repeat Cardiac Surgery. Anesthesia \& Analgesia, 84, 990-996. https://doi.org/10.1213/00000539-199705000-00008

[5] Ker, K., Edwards, P., Perel, P., Shakur, H. and Roberts, I. (2012) Effect of Tranexamic Acid on Surgical Bleeding: Systematic Review and Cumulative Meta-Analysis. BMJ, 344, e3054. https://doi.org/10.1136/bmj.e3054

[6] Chauhan, S., Bisoi, A., Kumar, N., Mittal, D., Kale, S., Kiran, U., et al. (2004) Dose Comparison of Tranexamic Acid in Pediatric Cardiac Surgery. Asian Cardiovascular and Thoracic Annals, 12, 121-124. https://doi.org/10.1177/021849230401200208

[7] Shimizu, K., Toda, Y., Iwasaki, T., et al. (2011) Effect of Tranexamic Acid on Blood Loss in Pediatric Cardiac Surgery: A Randomized Trial. Journal of Anesthesia, 25, 823-830. https://doi.org/10.1007/s00540-011-1235-Z

[8] Schindler, E., Photiadis, J., Sinzobahamvya, N., Dores, A., Asfour, B. and Hraska, V. (2011) Tranexamic Acid: Analternative to Aprotininas Antifibrinolytic Therapy in Pediatric Congenital Heart Surgery. European Journal of Cardio-Thoracic Surgery, 39, 495-499. https://doi.org/10.1016/j.ejcts.2010.07.026

[9] Lin, C.-Y., Shuhaiber, J.H., Loyola, H., Liu, H., del Nido, P., DiNardo, J.A., et al. The Safety and Efficacy of Antifibrinolytic Therapy in Neonatal Cardiac Surgery. PLoS $O N E, 10$, e0126514. https://doi.org/10.1371/journal.pone.0126514

[10] Bahnson, H. and Ziegler, R. (1950) A Consideration of the Causes of Death Following Operation for Congenital Heart Disease of the Cyanotic Type. Surgery, Gynecology \& Obstetrics, 90, 60-76.

[11] Gill, J.C., Wilson, A.D., Endres-Brooks, J. and Montgomery, R.R. (1986) Loss of the Largest von Willebrand Factor Multimer from the Plasma of Patients with Congenital Cardiac Defects. Blood, 67, 758-761.

[12] Stammers, A.H., Rauch, E.D., Willett, L.D., Newberry, J.W. and Duncan, K.F. 
(2000) Pre-Operative Coagulopathy Management of a Neonate with Complex Congenital Heart Disease: A Case Study. Perfusion, 15, 161-168. https://doi.org/10.1177/026765910001500212

[13] McMullan, V. and Alston, R.P. (2010) The Effect of the Suspension of the License for Aprotinin on the Care of Patients Undergoing Cardiac Surgery: A Survey of Cardiac Anesthesiologists' and Surgeons' Opinions in the United Kingdom. Journal of Cardiothoracic and Vascular Anesthesia, 24, 418-421.

https://doi.org/10.1053/j.jvca.2009.10.028

[14] Sniecinski, R.M., Chen, E.P., Makadia, S.S., Kikura, M., Bolliger, D. and Tanaka, K.A. (2010) Changing from Aprotinin to Tranexamic Acid Results in Increased Use of Blood Products and Recombinant Factor VIIa for Aortic Surgery Requiring Hypothermic Arrest. Journal of Cardiothoracic and Vascular Anesthesia, 24, 959-963. https://doi.org/10.1053/j.jvca.2010.02.018

[15] Strouch, Z., Drum, M. and Chaney, M. (2009) Aprotinin Use during Cardiac Surgery: Recent Alterations and Effects on Blood Product Utilization. Journal of Clinical Anesthesia, 21, 502-507. https://doi.org/10.1016/j.jclinane.2008.12.021

[16] Breuer, T., Martin, K., Wilhelm, M., Wiesner, G., Schreiber, C., Hess, J., Lange, R. and Tassani, P. (2009) The Blood Sparing Effect and the Safety of Aprotinin Compared to Tranexamic Acid in Paediatric Cardiac Surgery. European Journal of Cardio-Thoracic Surgery, 35, 167-171. https://doi.org/10.1016/j.ejcts.2008.09.038

[17] de Leede-van der Maarl, M.G., Hilkens, P. and Bosch, F. (1999) The Epileptogenic Effect of Tranexamic Acid. Journal of Neurology, 246, 843. https://doi.org/10.1007/s004150050466

[18] Hui, A.C., Wong, T.Y., Chow, K.M. and Szeto, C.C. (2003) Multifocal Myoclonus Secondary to Tranexamic Acid. Journal of Neurology, Neurosurgery, and Psychiatry, 74, 547. https://doi.org/10.1136/jnnp.74.4.547

[19] Martin, K., Wiesner, G., Breuer, T., Lange, R. and Tassani, P. (2008) The Risks of Aprotinin and Tranexamic Acid in Cardiac Surgery: A One-Year Follow-Up of 1188 Consecutive Patients. Anesthesia \& Analgesia, 107, 1783-1790. https://doi.org/10.1213/ane.0b013e318184bc20

[20] Hardy, J., Belisle, S., Dupont, C., Harel, F., Robitaille, D., Roy, M. and Gagnon, L. (1998) Prophylactic Tranexamic Acid and Epsilon-Aminocaproic Acid for Primary Myocardial Revascularization. The Annals of Thoracic Surgery, 65, 371-376. https://doi.org/10.1016/S0003-4975(97)01016-3

[21] Katsaros, D., Petricevic, M., Snow, N.J., Woodhall, D.D. and Van Bergen, R. (1996) Tranexamic Acid Reduces Post-Bypass Blood Use: A Double-Blinded, Prospective, Randomized Study of 210 Patients. The Annals of Thoracic Surgery, 61, 1131-1135. https://doi.org/10.1016/0003-4975(96)00022-7

[22] Karski, J.M., Teasdale, S.J., Norman, P., Carroll, J., VanKessel, K., Wong, P. and Glynn, M.F. (1995) Prevention of Bleeding after Cardiopulmonary Bypass with High-Dose Tranexamic Acid. Double-Blind, Randomized Clinical Trial. The Journal of Thoracic and Cardiovascular Surgery, 110, 835-842. https://doi.org/10.1016/S0022-5223(95)70118-4

[23] Brown, J.R., Birkmeyer, N.J. and O’Connor, G.T. (2007) Effectiveness and Adverse Outcomes of Antifibrinolytic Agents in Cardiac Surgery. Circulation, 115, 2801-2813. https://doi.org/10.1161/CIRCULATIONAHA.106.671222

[24] Henry, D., Carless, P., Fergusson, D. and Laupacis, A. (2009) The Safety of Aprotinin and Lysine-Derived Antifibrinolytic Drugs in Cardiac Surgery: A Meta-Analysis. CMAJ, 180, 183-193. https://doi.org/10.1503/cmaj.081109 
[25] Ngaage, D.L. and Bland, J.M. (2010) Lessons from Aprotinin: Is the Routine Use and Inconsistent Dosing of Tranexamic Acid Prudent? Meta-Analysis of Randomised and Largematched Observational Studies. European Journal of Cardio- Thoracic Surgery, 37, 1375-1383. https://doi.org/10.1016/j.ejcts.2009.11.055

\section{Abbreviations}

ASO: Arterial Switch Operation

BD Glenn: Bidirectional Glenn shunt

CPB: Cardio Pulmonary Bypass

DORV: Double Outlet Right Ventricle

ECG: Electrocardiogram

EEG: Electroencephalogram

ECMO: Extra Corporeal Membrane Oxygenation

FFP: Fresh Frozen Plasma

Hb: Haemoglobin

ICR: Intra Cardiac Repair

ICU: Intensive Care Unit

MPA: Main Pulmonary Artery

PS: Pulmonary Stenosis

SCIMITAR syndrome: Anomalous Right pulmonary venous drainage in to Inferior Vena Cava, associated with hypoplastic Right lung

TA: Tranexamic Acid

TOF: Tetralogy of Fallot

TAPVC: Total Anomalous Pulmonary Venous Connection

TGA: Transposition of Great Arteries

VSD: Ventricular Septal Defect 